Paidéia, 2006, 16(34), 263-273

\title{
DIFERENÇAS DE GÊNERO NO BRINCAR DE CRIANÇAS PRÉ-ESCOLARES E ESCOLARES NA BRINQUEDOTECA ${ }^{1}$
}

\author{
Fernanda Wanderlind \\ Gabriela Dal Forno Martins \\ Janete Hansen \\ Samira Mafioletti Macarini \\ Mauro Luis Vieira ${ }^{2}$ \\ Universidade Federal de Santa Catarina
}

\begin{abstract}
Resumo: Este estudo teve como objetivo principal caracterizar o brincar de meninos e meninas em duas brinquedotecas, uma na pré-escola e outra no ensino fundamental. Participaram do primeiro nove meninos e dez meninas; e do segundo, onze meninas e treze meninos. Em ambos os contextos, verificaram-se a predominância de brincadeiras entre crianças de mesmo sexo. Houve predomínio de brincadeiras solitárias na pré-escola, e de brincadeiras em grupo no ensino fundamental. Meninas, nos dois contextos, brincaram significativamente mais de faz-de-conta e com brinquedos para o desenvolvimento afetivo do que meninos. Estes, em comparação com meninas, na pré-escola, brincaram significativamente mais de brincadeira realística e com brinquedos que reproduzem o mundo técnico. No ensino fundamental, meninos brincaram significativamente mais de brincadeira turbulenta e sem brinquedo do que meninas. Os resultados são discutidos com base nas características das crianças e também em função dos contextos das brinquedotecas.
\end{abstract}

Palavras-chave: brincadeira; brinquedoteca; desenvolvimento infantil.

\section{GENDER DIFFERENCES IN PLAY OF PRE-SCHOLAR AND SCHOLAR'S CHILDREN AT TOY-LIBRARY}

Abstract: The purpose of this study was to characterize playing of boys and girls in two toy-libraries, one in a day care center, another in an elementary school. Nine boys and ten girls participated of first; eleven girls and thirteen boys were the subjects of the second. In both contexts, it was verified predominance of social play between children of same gender. There was predominance of solitary play in day care center, and play in groups in elementary school. Girls, in the two contexts, played significantly more of the pretend play and with toys for the affective development than boys. Those, compared to girls, in day care center showed significantly more realistic play and with toys that reproduce the technical world. In the elementary school, boys showed significantly more turbulent and without toys plays than girls. The results are discussed on the basis of children's characteristics and of the toy-libraries contexts.

Key words: play; toy-library; child development.

Diversos aspectos do comportamento de brincar vêm sendo estudados ao longo dos anos, tais como sua relação com o desenvolvimento (Pellegrini \& Smith, 1998), o brincar enquanto meio de transmissão e ressignificação da cultura na qual a criança está inserida (Conti \& Sperb, 2001; Carvalho \& Pedrosa, 2002; Pontes \& Magalhães, 2003), aspectos univer-

\footnotetext{
${ }^{1}$ Recebido em 03/07/06 e aceito para publicação em 13/11/06.

${ }^{2}$ Endereço para correspondência: Mauro Luis Vieira, Departamento de Psicologia da Universidade Federal de Santa Catarina - Campus Universitário, Trindade, CEP: 88040-900, Florianópolis- SC, Email: mvieira@cfh.ufsc.br
}

sais da interação no brincar, incluindo semelhanças e diferenças entre os gêneros (Martin \& Fabes, 2001) e entre diferentes contextos culturais (Gosso, 2004; Morais, 2004). Essa diversidade de enfoques contempla a afirmação de Rabinovich (2003) acerca da natureza do brincar, que ela diz que pode ser pensado como um comportamento adaptado e adaptativo da espécie. Adaptado porque, visto de um tempo longo, é comum a todos os membros da espécie; já de um tempo curto é adaptativo, porque se todos da espécie brincam varia o como, onde, com quê e com quem brincam. 


\section{Fernanda Wanderlind}

Embora a brincadeira seja uma atividade universal entre as crianças de diferentes populações, cada cultura possui uma forma peculiar de expressão que é reflexo das características ambientais específicas (Gosso, 2004). Segundo Morais (2004), tanto a brincadeira como os brinquedos que ela pode envolver, estão marcados pela identidade cultural e por características sociais específicas de um grupo social. Diante disso, pode-se dizer que ao mesmo tempo em que a brincadeira se constitui como uma característica universal, ela possui aspectos específicos que irão depender de diversos fatores, tais como ambientes físicos, sociais, culturais e as características da criança.

Com relação ao que pode influenciar o brincar, Morais e Otta (2003) introduzem o conceito de zona lúdica, correspondente ao espaço em que ocorre o brincar, o qual é constituído, por três elementos: 1) a criança com suas experiências, seus recursos, suas motivações, pressões e condições sociais que a cercam; 2) o espaço físico em que ela está inserida, como os brinquedos que ela tem acesso; e 3 ) o espaço temporal com o tempo dedicado à brincadeira, as relações e crenças familiares. Tais elementos podem influenciar o brincar, garantindo-lhe um aspecto específico em cada contexto.

\section{Brincadeiras de meninos e meninas}

As diferenças de gênero no brincar infantil foram verificadas por diversos estudos (Moraes, 2001; Martin \& Fabes, 2001; Souza \& Rodrigues, 2002) e são importantes na medida em que possibilitam que meninos e meninas desenvolvam-se de maneira diferenciada, adquirindo habilidades diversificadas e, dessa forma, distinguindo seu papel de gênero de acordo com a sociedade e cultura nas quais estão inseridos. Segundo Katz e Boswell (1986), o papel de gênero vem sendo conceituado como um conjunto organizado de expectativas para comportamentos e atividades que são considerados apropriados e esperados pelos outros, tanto para homens quanto para mulheres, de uma determinada cultura. O conceito também inclui comportamentos atuais, preferências e atitudes juntamente com expectativas da sociedade, formando uma relação entre comportamento individual e normas prescritas culturalmente.

A concepção evolucionista, sem negar o caráter social das diferenças de gênero, explica tais dife- renças com base na interdependência dos aspectos filogenéticos e culturais do desenvolvimento humano (interacionista), que teriam sido consolidadas no ambiente de adaptação da espécie; ou seja, é possível que o ambiente em que viveram os ancestrais humanos tenha dotado homens e mulheres de propensões comportamentais diferentes (Hinde, 1987), que estariam ligadas a sistemas de crenças e valores estabelecidos através da cultura (Maccoby, 1988). Dessa forma, a criança já nasce com determinadas predisposições relacionadas às diferenças entre os gêneros, que seriam fortalecidas ou não pela influência do ambiente e da cultura.

Preferências sexualmente estereotipadas ${ }^{1}$ foram identificadas aos 18 meses de idade (Beraldo, 1993), e podem ser consideradas como eliciadoras da segregação de gênero no brincar infantil (Maccoby, 1988). Aos três anos de idade, as crianças já possuem uma capacidade definida de atribuir rótulos de gênero, tanto a si, como aos outros, demonstrando preferência por brincar com grupos do mesmo sexo, o que se mantém até boa parte do ensino fundamental, apesar de a maioria das crianças também participar de grupos mistos (Beraldo, 1993).

Outros fatores também podem estar relacionados à existência de segregação no brincar infantil, conforme salienta Beraldo (1993). Um deles é a presença de indícios de que os meninos não aceitam o estilo de influência das meninas (baseado na argumentação e persuasão), e as meninas, não aceitam o dos meninos (baseado na força física). Outro fator são as brincadeiras irônicas feitas pelas crianças quando um menino e uma menina se envolvem na mesma brincadeira, junto com a percepção do sexo contrário como um parceiro romântico potencial futuro. Ainda há o fato de que os meninos gostam de brincadeiras mais brutas e barulhentas, e por isso, procuram parceiros do mesmo sexo, porque estes vão responder de forma mais positiva ao "convite" do que as meninas.

As preferências estereotipadas de meninos e meninas estão relacionadas aos brinquedos utilizados, aos tipos de brincadeira e aos temas do faz-de-conta.

\footnotetext{
${ }^{1}$ Por estereotipia, entende-se a preferência distinta de meninos e meninas por determinados brinquedos e brincadeiras. Enquanto que a segregação de gênero está relacionada a preferência, tanto de meninos quanto de meninas por brincadeiras em grupos homogêneos, ou seja, meninos geralmente brincam entre si e meninas também.
} 
As meninas, em geral, brincam mais com bonecas e seus acessórios, objetos domésticos, além de brinquedos macios, preferem atividades manuais e gostam de dançar, cantar e fantasias (Bichara, 1994a). Possuem preferência também por eventos festivos e domésticos, como casamentos, nascimentos e namoros enquanto os meninos preferem blocos, veículos, ferramentas e brincadeiras movimentadas - pular, correr - assim como temas de super-heróis (Bichara, 1994b; Pellegrini \& Smith, 1998).

Com relação aos tipos de brincadeiras, Gosso (2004) verificou junto às crianças Parakanãs, que as meninas brincaram mais de contingência social do que os meninos. Por brincadeira de contingência social a autora entende aquela que envolve um esquema de revezamento social, aparentemente motivada e reforçada pelo prazer associado à capacidade de produzir respostas contingentes nos outros e de responder contingentemente aos outros (esconde-esconde, fazer cócegas, imitar gestos ou vocalizações). Ela constatou também que meninos e meninas desenvolvem atividades de construção, porém o produto da brincadeira é diferente. Por exemplo, meninos caçadores-coletores e/ou indígenas constroem estruturas, machados, lanças, estilingues e arcos e flechas como os pais, enquanto as meninas fazem panelas de barro, cestos de palha e bonecas (Gosso, 2004).

No caso específico das brincadeiras de fazde-conta, embora existam preferências, o tema pode variar de acordo com os suportes disponíveis (Pellegrini \& Smith, 1998), ou seja, ser regulado pelas características dos objetos e pessoas sobre os quais a criança imprime suas transformações simbólicas (Bichara, 1994b). Meninos talvez imitem super-heróis (modelo fantástico) por não estarem em contato direto com os pais, que poderiam servir de exemplo, já as meninas brincam mais com modelos realísticos (Morais \& Otta, 2003). Ainda sobre o faz-de-conta, Pellegrini e Smith (1998) afirmam que meninos quando brincam com brinquedos considerados femininos (como bonecas) sua brincadeira é menos sofisticada do que quando o fazem com os considerados masculinos (blocos, por exemplo). Durante a pré-escola, ainda segundo os autores anteriormente citados, as meninas brincam com mais freqüência e em graus mais sofisticados quando comparadas com meninos.

\section{O espaço da brinquedoteca}

Os comportamentos infantis são influenciados pelo ambiente físico e social no qual as crianças estão inseridas (Meneghini \& Campos-de-Carvalho, 2003). Dessa forma, diferentes maneiras de organizar o espaço oferecem suporte para formas diversas formas de contato social. Alguns autores têm caracterizado tipos de estruturação do ambiente em creches, que influenciam na interação social das crianças (Meneghini \& Campos-de-Carvalho, 2003; Campos-de-Carvalho \& Padovani, 2000). Uma dessas formas é a brinquedoteca, um espaço estruturado para estimular a criança a brincar, possibilitando o acesso a grande variedade de brinquedos, dentro de um ambiente especialmente lúdico.

A brinquedoteca, sendo um local propício para estimular a criatividade, é preparada de forma que seus espaços incentivem a brincadeira de 'faz-deconta', a dramatização, a construção, a solução de problemas, a socialização e o desejo de inventar (Kishimoto, 1998). Algumas brinquedotecas, por exemplo, além de possuírem espaços abertos (possibilitam à criança uma visão de todo o local), têm também espaços restritos (presença de barreiras físicas que dividem o local em duas ou mais áreas), que são estruturados utilizando temáticas diferenciadas, permitindo, assim, uma grande variedade de brincadeiras.

Os relatos de pesquisas e reflexões acerca do brincar expostos anteriormente, permitem comprender que este é considerado um comportamento universal, típico da espécie humana; ao mesmo tempo, que ele é altamente modulado por características do contexto em que ocorre, o que implica na qualidade da brincadeira e conseqüentemente no desenvolvimento da criança. Diante disso, o principal objetivo deste trabalho foi caracterizar o brincar de meninos e meninas na brinquedoteca em dois contextos educacionais (Educação Infantil e Ensino Fundamental). É importante ressaltar que a escolha pela realização da pesquisa em dois contextos não implica numa comparação dos dados resultantes da coleta nesses locais, mas sim em entender de que forma as características das crianças e do contexto atuam na modulação do brincar. Os resultados deste e de estudos similares tornam-se relevantes na medida em que podem permitir a valorização de diferentes contextos 
de desenvolvimento, além da identificação de aspectos a serem aprimorados nesses contextos para implementação da brincadeira.

\section{Método}

A coleta de dados deu-se por meio de dois estudos realizados segundo metodologia semelhante, porém em instituições educacionais diferentes, sendo o Estudo 1 na Educação Infantil e o Estudo 2 no Ensino Fundamental. Os locais de coleta de dados de ambos foram as brinquedotecas das respectivas instituições, que eram freqüentadas pelas crianças como uma atividade curricular.

\section{Participantes:}

Para ambos os estudos as crianças participantes foram escolhidas por meio de um sorteio, sendo que aquelas que não compareciam com freqüência as brinquedotecas foram excluídas ou substituídas por outras aleatoriamente.

\section{Estudo 1:}

Grupo de participantes composto por 19 crianças (10 meninas e 9 meninos), matriculadas em período integral em uma creche filantrópica localizada em Florianópolis (SC). A idade das crianças, ao final das sessões de observação, variou entre 5 anos e 3 meses a 6 anos e 8 meses ( $M=6$ anos). Eram crianças pertencentes a famílias de classe com baixo poder aquisitivo, moradoras próximo da creche, sendo que grande parte delas, segundo as professoras, sem acesso a uma diversidade de brinquedos em casa.

\section{Estudo 2:}

Os participantes foram 24 crianças (11 meninas e 13 meninos) de $1^{\mathrm{a}}$ e $2^{\mathrm{a}}$ série, matriculadas em uma escola pública de Ensino Fundamental associada à Universidade Federal de Santa Catarina. A idade das crianças, ao final das sessões de observação, variou entre 7 anos e 5 meses a 10 anos ( $M=8$ anos e 6 meses). Esta escola atende a crianças dos mais diversos níveis econômicos, visto que as vagas são distribuídas através de um sorteio.

\section{Locais de observação: \\ Estudo 1:}

A creche em que foi realizado esse estudo atende crianças de 6 meses a 7 anos de idade. As salas são distribuídas em 2 pavimentos, mas o espaço é restrito e materiais como brinquedos também o são.
O pátio contém brinquedos como balanço, trepa-tre$\mathrm{pa}$, casinha de bonecas, escorregador e gangorra.

A brinquedoteca fica no pavimento superior e mede aproximadamente $10 \mathrm{~m}^{2}$. Há uma mesa de escritório em uma das paredes, na qual as crianças pintam, desenham e fazem bijuterias. Na parede perpendicular há 2 armários nos quais ficam guardados os brinquedos disponíveis. No chão há um tapete emborrachado de montar com figuras de animais e letras. Há uma porta e uma janela na sala que conta também com iluminação artificial.

As crianças freqüentam a brinquedoteca em grupos de 10, permanecendo na brinquedoteca em torno de 1 hora por semana. Durante esse período elas brincam livremente utilizando os brinquedos disponíveis, sendo monitoradas por uma brinquedista.

\section{Estudo 2 :}

A escola em que foi realizado esse estudo possui uma brinquedoteca com espaço de aproximadamente $25 \mathrm{~m}^{2}$, com diversos brinquedos destinados a propiciar variedade de brincadeira. Há:1) o tapete, localizado no centro da sala e sobre o qual existem diversas almofadas em forma de animais; 2) o espaço da parede, onde fica uma lousa e brinquedos como carrinhos de boneca e supermercado, bonecas, bebês, berço, mesinha com louças, mini fogão, entre outros; 3 ) uma mesinha com oito cadeiras; e 4) o canto da beleza, onde estão dispostos dois espelhos, um criado mudo, um baú e um cabideiro, sendo estes dois últimos utilizados para guardar diversas fantasias.

As crianças usam o espaço e os brinquedos livremente, uma vez por semana, durante um período de 45 minutos, em horário curricular. Em cada período quinze crianças freqüentam o local e são monitoradas por uma brinquedista.

\section{Procedimentos de coleta dos dados}

Após a aprovação do projeto pelo Comitê de Ética em Pesquisas com Seres Humanos (163/04 e 124/05), foram realizadas observações diretas de brincadeira livre utilizando-se o método de observação por sujeito focal e por amostragem de tempo (30 em 30 segundos). Todas as crianças foram observadas nos horários de atividade livre na brinquedoteca. Foram realizadas seis observações de cinco minutos para cada criança, totalizando 30 minutos por criança. A ordem em que foram observadas foi aleatória, procu- 
rando não repetir observações de uma mesma criança no mesmo dia. Para determinar a fidedignidade da coleta de dados, uma etapa inicial foi realizada com dois observadores, que registraram independentemente $25 \%$ dos eventos de brincadeira. O índice de concordância para cada categoria de comportamento foi de no mínimo $80 \%$.

\section{Instrumento}

Para o procedimento de observação de brincadeira livre das crianças na brinquedoteca, construiuse um protocolo composto por categorias comportamentais, após os dados de identificação: nome, grupo, série e sexo.

Tipo de Interação (ou ausência dela): o número de envolvidos no episódio de brincar: a) sozinha: não há contato com nenhuma outra criança; b) díade: brinca com só mais uma ; e c) grupo: criança brinca com duas ou mais colegas.

Composição grupal segundo o gênero: a) Grupo homogêneo: criança focal brinca com parceiros infantis de mesmo sexo; b) Grupo misto: criança focal brinca com parceiros infantis de sexo oposto ou de ambos os sexos.

Presença de adulto: a criança brinca na presença de um adulto, podendo este estar interagindo ou apenas observando o evento de brincadeira.

Tipo de brinquedo: brinquedo (ou ausência dele) utilizado no evento de brincadeira, baseado em um modelo de categorias elaborado pelo International Council of Children's Play (ICCP) (Michelet, 1998). Um ou mais brinquedos poderiam ser registrados no mesmo intervalo, sendo sete as categorias, a saber: a) Brinquedos para primeira idade $\mathrm{e}$ atividades sensório-motoras - como quadros de atividades com peças coloridas, de formas diversas; brinquedos para empurrar, puxar, rolar; bolas e cubos em tecido entre outros; b) Brinquedos para atividades físicas - bolas, petecas, cordas, boliches, jogo de argolas, peças para atirar em alvo; c) Brinquedos para atividades intelectuais - quebra-cabeças; de montar por superposição ou encaixe; materiais didáticos como papel, lápis, livros; jogos pedagógicos; d) Brinquedos que reproduzem o mundo técnico - veículos, bonecos e aparelhos em miniatura; objetos transformáveis, robôs; e) Brinquedos para o desenvolvimento afetivo - pelúcia, bonecas, bebês, acessórios para bonecas (rou- pas, bijuterias), louças, panelinhas, fogões, miniaturas de figuras (animais), acessórios de beleza (maquiagem, bolsas, bijuterias); f) Brinquedos para atividades criativas - como almofadas, instrumentos musicais, mosaicos, dobraduras, fantoches; materiais recicláveis; quadro-negro e giz; g) Brinquedos para relações sociais - jogos de carta, de estratégia, de percurso, de interpretação, entre outros.

Além destas categorias de brinquedos formuladas pela ICCP, foram criadas, para o presente estudo, duas novas categorias: $h$ ) fantasia, a qual abrange roupas de carnaval, super-herói, palhaço, bichos, personagens infantis, máscaras, vestidos, chapéis, perucas, bijuterias, entre outros; e i) sem brinquedo, quando a criança brinca sem utilizar objetos.

No caso da brinquedoteca do Estudo 1, não estavam disponíveis no espaço fantasias, brinquedos para atividades físicas e sensório-motoras.

Tipo de brincadeira: classificação baseada em uma combinação dos critérios de Moraes (2001) e Morais e Otta (2003): a) faz-de-conta - brincadeiras que incluem tratar os objetos como se fossem outros, atribuir-lhes propriedades diferentes das que realmente possuem, atribuir a si e aos outros papéis diferentes dos habituais, criar cenas imaginarias e representá-las; b) realística - situações em que a criança praticamente não utiliza o faz-de-conta e apresenta interação real com a situação de brincadeira. Inclui-se aí os jogos sociais de regras (envolvem a rituali-zação de papéis, um ciclo repetitivo de ações e, em geral, são competitivos) e as brincadeiras de construção (materiais são combinados para a criação de um produto novo: construir, encaixar, empilhar); c) turbulenta - ocorre quando a criança exibe movimentos bruscos, semelhantes aos de uma luta, porém manifestando expressão facial hilariante, ao mesmo tempo em que o oponente "atacado" não demonstra nenhuma expressão de ressentimento (atividades que envolvem luta perseguição e fuga, provocação e zombaria, rolar em dupla no chão, encostar no colega de forma brusca); e d) outros comportamentos - caso a criança não estivesse envolvida em uma dessas atividades lúdicas, registrava-se que ela estava em outro comportamento (vestindo fantasia, caminhando, conversando com o colega, discutindo regras, entre outros). 


\section{Análise dos dados}

Após a coleta dos dados, esses foram lançados em uma planilha do programa estatístico SPSS (Statistical Package for Social Sciences - versão 11.5). Através do software foi possível realizar análises estatísticas descritivas, principalmente porcentagens, e um teste de comparação entre médias (teste t), envolvendo meninos e meninas.

\section{Resultados}

Cada intervalo de observação teve duração de 30 segundos, sendo que para cada criança o número total de intervalos observados foi igual a 60 . Os resultados a seguir serão expostos através de porcentagens e médias calculadas em função deste número de intervalos de observações por criança. Em ambos os estudos, os resultados foram organizados de acordo com as categorias de observação expostas anteriormente.

\section{ESTUDO 1}

\section{Tipo de interação}

Quanto ao tipo de interação, 53\% das brincadeiras de meninas foram solitárias, enquanto $37 \%$ foram em díades e $10 \%$ em grupo. Já entre os meninos, $48 \%$ de suas brincadeiras foram solitárias, $33 \%$ em díades e $19 \%$ em grupo. Para testar o efeito de gênero sobre as médias de participação em brincadeira nos diversos tipos de interação utilizou-se o teste-t. Essa análise não revelou efeito de interação entre essas variáveis.

\section{Gênero e Composição do Grupo}

Para verificar a existência de segregação no brincar infantil, foram comparadas as proporções de participação das crianças em brincadeiras de grupos de mesmo sexo e de grupos mistos. Do total de brincadeiras, $66 \%$ delas foram de mesmo sexo e $44 \%$ foram mistas, ou seja, envolviam ambos os sexos. Por meio da comparação das médias de intervalos que envolviam brincadeiras homogêneas e mistas (teste $t$ ) verificou-se que a diferença entre tais médias foi estatisticamente significativa $(\mathrm{t}=2,54 ; \mathrm{df}=18 ; \mathrm{p}=0,05)$, confirmando a existência de segregação no brincar dessas crianças. A variável gênero não influenciou na composição do grupo de acordo com o teste-t, o que demonstra que a segregação não foi maior em nenhum dos grupos, nem em meninos, nem em meninas.

\section{Participação nos diferentes tipos de brin- cadeiras}

As crianças passaram $82 \%$ do tempo brincando e apenas $18 \%$ do tempo em outros comportamentos. Quando estavam brincando, as meninas se envolveram em $61,5 \%$ dos intervalos em brincadeiras realísticas e $38,5 \%$ no faz-de-conta. No caso dos meninos, $86 \%$ de suas participações foram em brincadeiras realísticas e $14 \%$ no faz-de-conta. Não foram verificados intervalos envolvendo a brincadeira turbulenta em nenhum dos grupos. O teste-t demonstrou efeito marginalmente significativo da variável gênero sobre a participação das crianças nas modalidades do brincar. Houve uma tendência por meninas brincarem mais de faz-de-conta que os meninos $(\mathrm{t}=1,97 ; \mathrm{df}=17 ; p<0,1)$ e meninos mais de brincadeira realística do que as meninas $(\mathrm{t}=1,96 ; \mathrm{df}=17 ; p<0,1)$.

\section{quedo}

Utilização das diversas modalidades de brin-

As porcentagens referentes à utilização das diversas modalidades de brinquedos nas brincadeiras de meninos e meninas são apresentadas na Figura 1. Para verificar possíveis diferenças de gênero sobre as médias de utilização dos vários tipos de brinquedos foi utilizado o teste-t. Esta análise revelou efeito estatisticamente significativo de gênero sobre os brinquedos relacionados com o desenvolvimento afetivo $(\mathrm{t}=2,44 ; \mathrm{df}=17 ; \mathrm{p}<0,05)$ e os relacionados com mundo técnico $(\mathrm{t}=2,43 ; \mathrm{df}=17 ; \mathrm{p}=0,05)$. Diante disso, em comparação com as meninas, os meninos brincaram mais com brinquedos que reproduzem o mundo técnico, enquanto que elas brincaram mais com brinquedos relacionados ao desenvolvimento afetivo.

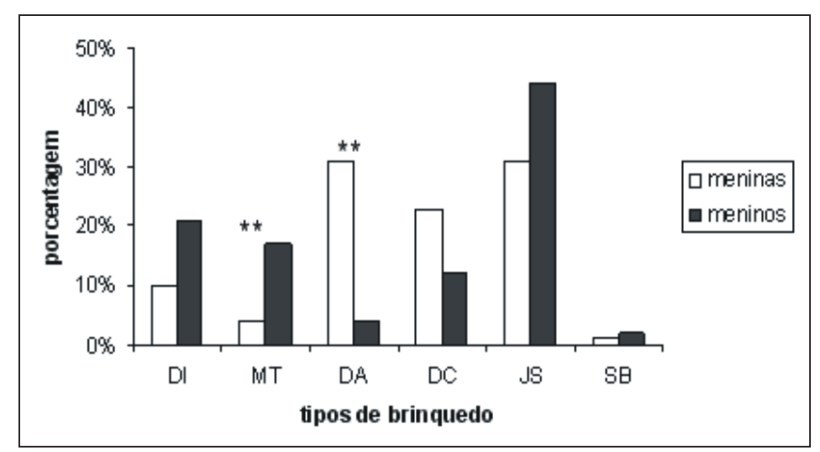

Figura 1: Porcentagem de utilização dos vários tipos de brinquedos por meninos e meninas no Estudo 1. $* *$ Diferença significativa $p=0,05$. 


\section{ESTUDO 2}

\section{Tipo de interação}

Quanto ao tipo de interação, 21\% das brincadeiras de meninas foram solitárias, enquanto $22 \%$ foram em díades e $57 \%$ em grupo. Já entre os meninos, $17 \%$ de suas brincadeiras foram solitárias, $31 \%$ em díades e $52 \%$ em grupo. Utilizou-se, então, testet para testar o efeito de gênero sobre as médias de participação em brincadeira nos diversos tipos de interação. Essa análise revelou efeito de interação marginalmente significativo sobre as díades $(\mathrm{t}=1,96$; $\mathrm{df}=22 ; p<0,1)$, mostrando uma tendência de que os meninos brincaram mais em díades $(M=19,31)$ do que as meninas $(M=13,55)$.

\section{Gênero e Composição do Grupo}

Para o total de eventos, a proporção de participação em brincadeiras de grupos de mesmo sexo (77\%) foi maior que a proporção de participação em brincadeiras de grupos mistos (23\%). Por meio da comparação das médias de intervalos que envolviam brincadeiras homogêneas e mistas (teste $t$ ) verificouse que a diferença entre tais médias foi estatisticamente significativa $(\mathrm{t}=7,49 ; \mathrm{df}=23 ; p=0,01)$, confirmando a existência de segregação no brincar dessas crianças.

A variável gênero, assim como no estudo 1 , não influenciou na composição do grupo de acordo com o teste-t, demonstrando que a segregação não foi maior em nenhum dos grupos, nem em meninos, nem em meninas.

\section{cadeira}

Participação nos diferentes tipos de brin-

As crianças passaram $79 \%$ do tempo observado brincando e apenas $21 \%$ do tempo em outros comportamentos (vestir fantasia, conversar com o colega, caminhar, entre outros). Com relação aos tipos de brincadeiras desenvolvidas pelos meninos, estes se envolveram em $40 \%$ dos intervalos com brincadeiras faz-de-conta, 38\% com brincadeiras realísticas e $22 \%$ com brincadeiras turbulentas. Já as meninas, desenvolveram a brincadeira de faz-de-conta em $59 \%$ dos intervalos de brincadeira, a realística em $36 \%$ e a turbulenta $5 \%$ e apresentaram.

$O$ teste-t revelou efeito significativo de gênero na participação de brincadeiras de faz-de-conta $(t=$
2,26; $\mathrm{df}=22 ; \mathrm{p}<0,05)$ e de brincadeiras turbulentas ( $\mathrm{t}$ $=3,17 ; \mathrm{df}=22 ; \mathrm{p}<0,01)$. As meninas brincaram mais de faz-de-conta que os meninos, enquanto estes brincaram mais de brincadeira turbulenta do que elas.

\section{quedo \\ Utilização das diversas modalidades de brin-}

Foram calculadas as proporções de utilização dos diversos tipos de brinquedo (ou ausência deles) por meninos e por meninas, as quais são apresentadas na Figura 2. Utilizou-se o teste-t para verificar possíveis diferenças de gênero sobre as médias de utilização dos vários tipos de brinquedos. Esta análise revelou efeito estatisticamente significativo de gênero sobre os brinquedos relacionados com o desenvolvimento afetivo $(\mathrm{t}=3,58 ; \mathrm{df}=22 ; \mathrm{p}<0,01)$, sobre as fantasias $(\mathrm{t}=2,8 ; \mathrm{df}=22 ; \mathrm{p}=0,01)$ e sobre categoria sem brinquedo $(\mathrm{t}=3,32 ; \mathrm{df}=22 ; \mathrm{p}<0,01)$. Além disso, revelou também efeito marginalmente significativo sobre os brinquedos associados ao desenvolvimento cognitivo $(\mathrm{t}=1,77$; $\mathrm{df}=22 ; \mathrm{p}<0,10)$ e ao desenvolvimento criativo $(\mathrm{t}=1,79 ; \mathrm{df}=22 ; \mathrm{p}<0,10)$. Diante disso, em comparação com as meninas, os meninos brincaram mais sem brinquedos e com brinquedos da categoria relacionada ao desenvolvimento criativo, enquanto que elas brincaram mais com brinquedos relacionados ao desenvolvimento cognitivo, afetivo e com as fantasias do que eles.

Figura 2: Porcentagem de utilização dos vários tipos de brinquedos por meninos e meninas no Estudo $2 * *$ Diferença significativa $=0,05 ; *$ Diferença marginalmente significativa $=0,1$.

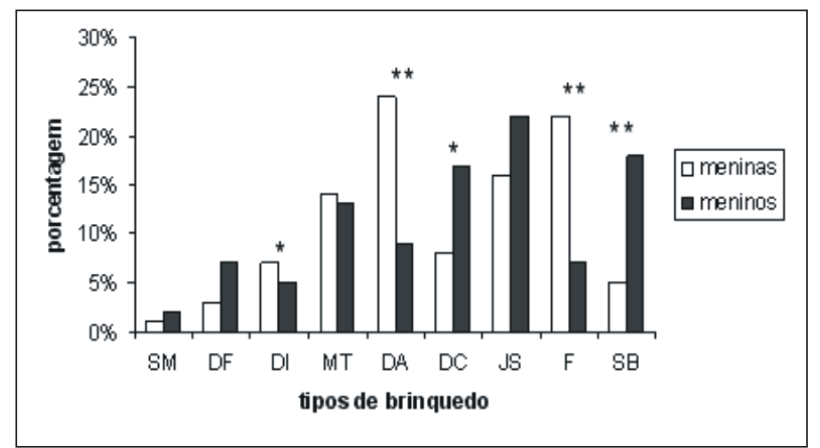

Legenda: Tipos de Brinquedos: SM-Sensório-Motor; DF-Desenvolvimento Físico; DI-Desenvolvimento Intelectual; MTBrinquedos que reproduzem o mundo técnico; DA-Desenvolvimento Afetivo; DC-Desenvolvimento Criativo; JS-Jogos Sociais; F-Fantasias; SB-Sem Brinquedo. 


\section{Fernanda Wanderlind}

\section{Discussão}

O principal objetivo da pesquisa foi caracterizar o brincar de crianças em dois contextos educacionais (Educação Infantil e Ensino Fundamental). Dessa forma, discutir-se-á em conjunto os resultados obtidos nos Estudo 1 e 2 quanto às diferentes categorias de análise.

Com os resultados obtidos quanto ao tipo de interação, foi verificado que as crianças do contexto pré-escolar (Estudo 1) brincaram mais sozinhas do que em grupos. Este resultado pode ter sido influenciado pelo espaço da brinquedoteca, o qual era bastante restrito e não possuía delimitação clara dos espaços envolvendo brinquedos. Já na brinquedoteca do Estudo 2 (contexto escolar), foi observado o contrário, houve predomínio da brincadeira em grupo. Neste local havia espaços que favoreciam a brincadeira em grupo, como por exemplo, o canto da beleza e principalmente o espaço central onde havia um tapete. A área desta brinquedoteca era maior do que a do Estudo 1, o que possivelmente possibilitou que as crianças brincassem em grupos sem a necessidade de disputar o espaço.

Ainda, quanto ao tipo de interação, outro fator que deve ser levado em conta são as diferenças socioeconômicas tanto das famílias das crianças participantes quanto das instituições. No caso do Estudo 1, em função de uma situação econômica menos favorecida, as crianças não têm acesso a muitos brinquedos nem em suas casas, nem nas salas de aula. Dessa forma, pode-se pensar que, quando foram expostas a um grande número de brinquedos novos e diferentes, possivelmente despenderam todo seu tempo e energia para explorar o máximo de brinquedos possíveis, o que não possibilitou a formação de grupos e a divisão de brinquedos com os colegas.

Outro resultado importante refere-se à ausência de efeito do gênero sobre o tipo de interação das crianças do Estudo 1 e a presença desse efeito no Estudo 2. Neste último foi constatado que os meninos brincaram mais em díades do que as meninas, resultado este contrário aos obtidos por Morais (2004), a qual verificou que as meninas tinham suas amizades mais focadas nas díades, e os meninos, nos grupos. Uma possível explicação é que na brinquedoteca do Estudo 2 era freqüente entre os meninos o jogo de botão, que ocorre somente em díade, e também a brincadeira turbulenta de lutinha, que em local fechado normalmente ocorreu em díades.

Quando as crianças se reuniam em duas ou mais para brincar, em ambos os estudos houve predominância da brincadeira entre grupos do mesmo sexo, o que demonstrou segregação no brincar. Este resultado já foi constatado por outros pesquisadores (Fabes, Martin \& Hanish, 2003; Souza \& Rodrigues, 2002; Martin \& Fabes, 2001; Morais, 2004).

Com relação aos tipos de brincadeiras, em ambos os contextos pesquisados, foram verificados predomínios tanto por parte das meninas quanto dos meninos das brincadeiras de faz-de-conta e realísticas em detrimento do brincar turbulento. Esse resultado já era esperado, uma vez que, em geral, as brinquedotecas são construídas de forma a propiciar maior ludicidade para as crianças, disponibilizando brinquedos e espaços capazes de estimular o aparecimento de diferentes tipos de brincadeiras, como o faz-de-conta, jogos de regras, entre outros. No entanto, as dimensões geralmente restritas desse espaço o caracterizam como não sendo um local apropriado para o aparecimento de brincadeiras que envolvem movimentos físicos amplos, como o brincar de lutinha e o pega-pega.

Entre as crianças com idade pré-escolar, esta última modalidade de brincadeira não apareceu em nenhum episódio observado, o que pode ser explicado justamente em função do restrito tamanho da brinquedoteca da instituição adicionado ao número de crianças que freqüentavam o espaço a cada vez (10 crianças). Os pesquisadores durante as observações puderam verificar a dificuldade que as crianças tinham em se distribuir pelo espaço e as estratégias por elas utilizadas visando aproveitá-lo da melhor forma (em função de as crianças brincarem muito próximas não havia possibilidade de crescimento dos grupos e algumas brincadeiras eram interrompidas pela passagem de outras crianças). Os participantes de idade escolar, todavia, se envolveram em diferentes proporções nas três modalidades de brincadeira, sendo o faz-de-conta a mais freqüente entre elas. Esse resultado provavelmente deve-se a qualidade do espaço em que estas crianças foram observadas ao brincar, o qual possuía, além de muitos brinquedos 
que favoreciam o aparecimento do faz-de-conta (como grande quantidade de fantasias, bebês, carrinhos, eletrodomésticos, animais), espaços destinados a essa modalidade, como o "canto da beleza" e a "casinha-circo".

Apesar de a brincadeira turbulenta, em relação aos demais tipos, ter aparecido em proporções menores no brincar das crianças do Estudo 2, verificou-se por meio da análise da variância que nesse contexto meninos brincaram mais desse tipo de brincadeira do que meninas, enquanto essas brincaram mais de faz-de-conta do que os meninos. Da mesma forma, no brincar das crianças da instituição pré-escolar houve uma tendência por meninas brincarem mais de faz-de-conta do que os meninos, enquanto entre estes verificou-se uma tendência por brincarem mais de brincadeiras realísticas do que as meninas. No ser humano, a propensão dos meninos para serem mais turbulentos do que as meninas durante a brincadeira foi correlacionada com a exposição de hormônios gonodais durante o desenvolvimento prenatal e neonatal (Collaer \& Hines, 1995). No caso de meninas, a brincadeira é menos centrada em papéis relacionados com o uso da força física e atividade motora ampla expressa publicamente(Biben, 1998) e, tendem a brincar mais de atividades relacionadas ao cuidado parental (brincar de bonecas) do que os meninos (Bjorklund \& Pellegrini, 2000).

Com relação ao tipo de brinquedo utilizado pelas crianças no brincar, as meninas, tanto no Estudo 1 quanto no Estudo 2, brincaram mais com brinquedos para o desenvolvimento afetivo do que meninos, tais como roupinhas, boneca, bichos de pelúcias, berçinho, bolsas, louças, fogão, entre outros. Esses resultados encontram-se em conformidade com a literatura, que coloca que o espaço familiar da casa é associado ao brincar das meninas e que elas procuram por brincadeiras que imitam a vida real, como atividades domésticas, casamentos e festas (Porto, 1998; Bichara, 1994a).

Quanto aos meninos, em ambos os estudos, os brinquedos mais utilizados por eles foram aqueles para as relações sociais, os quais envolvem, principalmente, os jogos de regras. Esse resultado está de acordo com um outro estudo observacional realizado na mesma brinquedoteca, o qual também verificou a predo- minância de utilização pelos meninos desse tipo de brinquedo (Macarini \& Vieira, 2006). Apesar desse tipo de brinquedo ter predominado entre os meninos, constatou-se que eles foram também bastante utilizados pelas meninas, o que indica que estes brinquedos favorecem trocas entre os diferentes sexos. Verifica-se a importância da utilização desses brinquedos para o desenvolvimento social das crianças, na medida em que podem oferecer uma forma livre e autônoma de interação entre elas. Através da brincadeira social, a criança é capaz de resgatar valores e sentimentos que são importantes para a vida adulta, como a responsabilidade, além de aprender a importância da negociação, da conquista, de conviver com regras e a resolver conflitos (Moraes, 2001).

Um outro tipo de brinquedo que também esteve bastante presente entre os meninos dos dois estudos, foi o brinquedo que reproduz o mundo técnico, como veículos, aparelhos em miniatura; objetos transformáveis, robôs, entre outros. Entre as crianças do contexto pré-escolar, verificou-se que meninos brincaram mais com esses brinquedos do que as meninas. Alguns autores, como Porto (1998) e Bichara (1994b), afirmam que meninos possuem preferência por brinquedos que reproduzem o universo externo e do trabalho, como brincadeiras que envolvem transportes e veículos, papéis com muita ação e super-heróis.

\section{Considerações Finais}

Os resultados dos presentes estudos fornecem indícios de que as diferenças entre os gêneros no brincar estão relacionadas a múltiplos fatores que interagem ao longo do processo de desenvolvimento. Pôde-se verificar que alguns resultados apontam para características universais no brincar, ao mesmo tempo em que outros revelam especificidades que dependem, dentre outros fatores, do contexto no qual está inserido. Essas características universais tais como a esteriotipia em relação às brincadeiras e aos brinquedos e a segregação, poderiam refletir diferenças consolidadas no ambiente de adaptação da espécie; ou seja, é possível que o ambiente em que viveram os ancestrais humanos tenha dotado homens e mulheres de propensões comportamentais diferentes, as quais são herdadas geneticamente.

Já com relação às especificidades de cada contexto, como a ausência de algumas brincadeiras e 
as diferentes formas de desempenhá-las, poderiam estar ligadas a sistemas de crenças e valores que são estabelecidos através da cultura, ao mesmo tempo em que dependeriam das características do espaço físico, como o tamanho e qualidade do espaço. Isso quer dizer que, apesar de as adaptações envolverem algum grau de controle genético, pois são passadas de uma geração a outra, a história ontogenética de cada criança tem papel importante na emergência e ativação dessas adaptações (Buss, Haselton, Shackelford, Bleske \& Wakefield, 1998).

A forma de compreender e investigar o comportamento de brincar que embasa a presente pesquisa, em conjunto com outros estudos tais como o de Gosso (2004), Morais (2004), contribui para o avanço do conhecimento acerca desse comportamento, apontando para sua natureza multidimensional. Esse conhecimento pode contribuir para que pais e educadores possam, durante sua prática cotidiana, valorizar o comportamento de brincar entre as crianças, além de proporcionar um ambiente adequado e diversificado que estimule a ludicidade, já que esta está intimamente relacionada ao desenvolvimento global da criança. Por fim, enfatiza-se a necessidade de novos estudos que venham a investigar as crenças de pais e educadores acerca do brincar, bem como as características individuais da criança que brinca.

\section{Referências}

Beraldo, K. E. A. (1993). Gênero de brincadeira na percepção de crianças de 5 a 10 anos. Dissertação de Mestrado. Instituto de Psicologia da Universidade de São Paulo, São Paulo.

Biben, M. (1998). Squirrel monkey playfighting: making the case for a cognitive training function for play. In M. Bekoff \& J. A.Byers (Eds.), Animal Play. Evolutionary, Comparative and Ecological Perspectives (pp.161-182). Cambridge: Cambridge University Press.

Bichara, I. D. (1994a). Um estudo etológico da brincadeira de faz-de-conta em crianças de 3-7 anos. Tese de Doutorado. Instituto de Psicologia da Universidade de São Paulo, São Paulo.

Bichara, I. D. (1994b). Brincadeira e cultura: o faz-de-conta das crianças Xocó e do Mocambo
(Porto da Folha/SE). Temas em Psicologia, v.7, n.1, 57-64.

Bjorklund, D. F. \& Pellegrini, A. D. (2000). Child Development and Evolutionary Psychology. Child Development, v.71,n.6, 1687-1708.

Buss, D. M.; Haseltom, M. G.; Shackelford, T. K.; Bleske, A. L. \& Wakefield, J. C. (1998). Adaptations, exaptations, and spandrels. American Psychologist, 53, 533-548.

Campos-de-Carvalho, M. I. \& Padovani, F. H. P. (2000). Agrupamentos preferenciais e não-preferenciais e arranjos espaciais em creches. Estudos de Psicologia, v.5, n.2, 443-470.

Carvalho, A. M. A. \& Pedrosa, M. I. (2002). Cultura no grupo de brinquedo. Estudos de Psicologia, v.7, n.1, 181-188.

Collaer, M. L. \& Hines, M. (1995). Human behavioral sex differences: a role for gonodal hormones early development? Psychological Bulletin, v.118, n.1, 55-107.

Conti, L. D. \& Sperb, T. P. (2001). O brinquedo de pré-escolares: um espaço de ressignificação cultural. Psicologia: Teoria e Pesquisa, v.17 n.1, 59-67.

Fabes, R. A. Martin, C. L. \& Hanish, L. D. (2003). Young children's play qualities in same, other, and mixed-sex peer groups. Child development. v.74, n.3, 921-932.

Gosso, Y. (2004). Pexe oxemoarai: brincadeiras infantis entre os índios Parakanã. Tese de Doutorado. Instituto de Psicologia da Universidade de São Paulo, São Paulo.

Hinde, R. A. (1987). Individuals, relationships and culture: Links between Ethology and Social Sciences. Cambridge: Cambridge University Press.

Katz, P. A. \& Bolswell, S. (1986). Flexibility and traditionality in children's gender roles. Genetic, Social and General Psychology Monographs. v.112 n.1, 103-47.

Kishimoto, T. M. (1998). Diferentes tipos de brinquedotecas. Em A. Friedmann (Org.), O direito 
de brincar: A brinquedoteca (pp. 49-59). São Paulo : Edições Sociais.

Macarini, S. M. \& Vieira, M. L. (2006). O brincar de crianças escolares na brinquedoteca. Revista Brasileira de Crescimento e Desenvolvimento Humano, v.16, n.1, 49-60.

Maccoby, E. E. (1988). Gender as a social category. Developmental Psychology, 24, 755-65.

Martin, C. L. \& Fabes, R. A. (2001). The stability and consequences of young children's samesex peer interactions. Developmental Psychology, v. 37, n.3, 431-446.

Meneghini, R. \& Campos-de-Carvalho, M. (2003). Arranjo espacial na creche: espaços para interagir, brincar isoladamente, dirigir-se socialmente e observar o outro. Psicologia: Reflexão e Crítica, v.16, n.2, 367-378.

Michelet, A. (1998). Classificação dos jogos e brinquedos: a classificação ICCP. Em A. Friedmann (Org.), O direito de brincar: A brinquedoteca (pp. 161-72). São Paulo : Edições Sociais.

Moraes, A S. (2001). Análise estrutural e funcional da brincadeira de crianças em idade pré-escolar. Dissertação de Mestrado. Universidade Federal de Santa Catarina, Florianópolis.

Morais, M. L. S. (2004). Conflitos e(m) brincadeiras infantis: Diferenças culturais e de gênero. Tese de Doutorado. Instituto de Psicologia da Universidade de São Paulo, São Paulo.

Morais, M. L. S. \& Otta, E. (2003). Entre a serra e o mar. Em A. M. A. Carvalho; C. M. C. Magalhães; F. A. R. Pontes \& I. D. Bichara (Orgs.), Brincadeira e cultura: viajando pelo Brasil que brinca. (pp. 127-157). São Paulo: Casa do Psicólogo.

Pellegrini, A. D. \& Smith, P. K. (1998). Physical activity play: The nature and function of a neglected aspect of play. Child development 69, 577598.

Pontes, F. A. R. \& Magalhães. C. M.C. (2003). A transmissão da cultura da brincadeira: algumas possibilidades de investigação. Psicologia: Reflexão e Crítica, v.16, n.1, 117-124.
Porto, C. L. (1998). Brinquedo e brincadeira na brinquedoteca. Em S. Kramer (Org.), Infância e produção cultural (pp. 171-198). São Paulo: Papirus.

Rabinovich, E. P. (2003). Nos tempos dos avós. Em A. M. A. Carvalho; C. M. C. Magalhães; F. A. R. Pontes \& I. D. Bichara (Orgs.), Brincadeira e cultura: viajando pelo Brasil que brinca.(pp. 930). São Paulo: Casa do Psicólogo.

Smith, P. K. \& Connoly, K. J. (1980). The ecology of preschool behavior. London: Cambridge University Press.

Souza, F. \& Rodrigues, M. M. (2002). A segregação sexual na interação de crianças de 8 e 9 anos Psicologia: Reflexão e Crítica, v.15, n.3, 489496. 